Thorax (1974), 29, 147.

\title{
The Clara cell
}

\author{
P. S M I TH, D. HEA TH, a nd H. MOOSA V I \\ The Department of Pathology, University of Liverpool
}

\begin{abstract}
Smith, P., Heath, D., and Moosavi, H. (1974). Thorax, 29, 147-163. The Clara cell. The ultrastructure of the bronchiolar Clara cell was examined in normal adult and neonatal rats, in similar animals which had been acutely exposed to hypoxia, and in adult rats following repeated doses of the anorexigen chlorphentermine. The Clara cell has all the features of a secretory cell, the product of secretion accumulating within smooth cisternae at the apex of the cell. The apical region is then extruded into the bronchiolar lumen in a process of apocrine secretion. Acute hypoxia accelerates this secretion in adult rats but has little effect upon neonatal rats. Administration of chlorphentermine induces a hyperplasia of Clara cells which is associated with large quantities of phospholipid free within the alveolar spaces and in macrophages. The Clara cells also contain accumulations of what appear to be phospholipid. This suggests that the Clara cell secretes the phospholipid pulmonary surfactant.
\end{abstract}

The bronchial tree has functions additional to the conduction of air into the alveoli. As well as the familiar ciliated cells the bronchial epithelium includes goblet cells, Feyrter cells, which we have described in a previous paper (Moosavi, Smith, and Heath, 1973), and Clara cells. Unlike goblet and Feyrter cells, which are located mostly in the bronchi, Clara cells are more numerous in the terminal bronchioles. Kölliker in 1881 noted them first but Clara (1937), after whom the cells are named, described them in detail (Azzopardi and Thurlbeck, 1969). Their ultrastructure was first described in mice by Karrer (1956) and in rabbits by Kisch (1958). Many Clara cells have apical club-shaped cytoplasmic processes (von Hayek, 1962; Azzopardi and Thurlbeck, 1969; Corrin, Etherton, and Conning, 1973) which most workers interpret as indicating a secretory function. Von Hayek (1962) thought the secretion to be mucus but Niden (1967) suggested it might be pulmonary surfactant. This latter idea has been subsequently supported by other workers (Etherton and Conning, 1971; Corrin, Etherton, and Conning, 1973; Etherton, Conning, and Corrin, 1973).

We have studied the ultrastructure of Clara cells in rats of different ages and in bronchioles of different calibre and the changes induced by exposure to acute hypoxia. If Clara cells are responsible for the synthesis of pulmonary surfactant, one might expect alterations in their structure and frequency in conditions involving excessive production of pulmonary phospholipid.
Accordingly we examined the Clara cells from rats given daily injections of chlorphentermine. a treatment which has been shown to produce large quantities of phospholipid in the alveolar spaces (Heath, Smith, and Hasleton, 1973; Smith, Heath, and Hasleton, 1973).

\section{MATERIALS AND METHODS}

The bronchioles from five groups of rats were examined (Table). The first group consisted of 10 adult albino rats, of which six were females of the Wistar strain and four were males of the Sprague Dawley strain. The second group comprised 12 neonatal Wistar rats which were 4 days old. No experimental procedures were performed on these two groups.

The third group comprised four adult female Wistar

T A B L E

AGE, STRAIN, AND TREATMENT OF RATS IN THE FIVE GROUPS

\begin{tabular}{|c|c|c|c|c|}
\hline Group & Strain & Age & $\begin{array}{l}\text { No. of } \\
\text { Rats }\end{array}$ & Treatment \\
\hline $\begin{array}{l}1 \\
1\end{array}$ & $\begin{array}{l}\text { Wistar } \\
\text { Sprague } \\
\text { Dawley }\end{array}$ & $\begin{array}{l}\text { Adult } \\
\text { Adult }\end{array}$ & $\begin{array}{l}6 \\
4\end{array}$ & $\begin{array}{l}\text { Control } \\
\text { Control }\end{array}$ \\
\hline $\begin{array}{l}2 \\
3\end{array}$ & $\begin{array}{l}\text { Wistar } \\
\text { Wistar }\end{array}$ & $\begin{array}{l}\text { Neonate } \\
\text { Adult }\end{array}$ & $\begin{array}{r}12 \\
4\end{array}$ & $\begin{array}{l}\text { Control } \\
\text { Subatmospheric } \\
\text { pressure of } \\
265 \mathrm{mmHg} \text { for } \\
12 \mathrm{hr}\end{array}$ \\
\hline 4 & Wistar & Neonate & 14 & $\begin{array}{l}\text { Subatmospheric } \\
\text { pressure of } \\
380 \mathrm{mmHg} \text { for } \\
24 \mathrm{hr}\end{array}$ \\
\hline 5 & $\begin{array}{l}\text { Sprague } \\
\text { Dawley }\end{array}$ & Adult & 20 & $\begin{array}{l}\text { Daily injections of } \\
\text { chlorphentermine }\end{array}$ \\
\hline
\end{tabular}


rats which were kept at a subatmospheric pressure of $265 \mathrm{mmHg}$ for 12 hours. This pressure simulated an altitude of approximately $29,000 \mathrm{ft}(8,840 \mathrm{~m})$ which was roughly equivalent to the summit of Mount Everest. The fourth group consisted of 14 neonatal Wistar rats of 4 days of age. These rats were kept for 24 hours at a pressure of $380 \mathrm{mmHg}$, simulating an altitude of $18,000 \mathrm{ft}(5,500 \mathrm{~m})$.

The conditions of hypoxia were achieved by placing the rats in a decompression chamber. Air was removed from the chamber with a vacuum pump while a spring-loaded inlet valve maintained the desired pressure within the chamber as well as replenishing the air supply. The mothers of the neonatal rats were also placed in the chamber to suckle their offspring but they were not used further in the experiments.

At the termination of each experiment the rats were killed with pentobarbitone sodium injected intraperitoneally. The thoracic cavity was opened and the thoracic organs were removed. Pieces of lung were excised and cut with a razor blade into small fragments measuring approximately $1 \mathrm{~mm}$ across. In the neonatal rats the tissue was taken from the hilum of the lung to maximize the chances of including large airways in the sections. The fragments of lung were transferred to bottles of ice-cold buffered glutaraldehyde $(6 \cdot 25 \%)$ and allowed to fix for 24 hours at $2-4^{\circ} \mathrm{C}$. They were then post-fixed in aqueous $1 \%$ osmium tetroxide, stained with alcoholic uranyl acetate, and embedded in Araldite. Sections $1 \mu \mathrm{m}$ thick were cut from the blocks and stained with toluidine blue for the selection of a suitable field. Those blocks which included a bronchiole were trimmed, and fine sections were cut with an Ultrotome III ultramicrotome using glass knives. The sections were floated onto copper grids, stained with lead citrate, and examined with an AEI EM 6B electron microscope using an acceleration voltage of $60 \mathrm{kV}$. Wherever possible both proximal and distal regions of bronchioles were examined from each rat. With the small pieces of tissue taken for electron microscopy it was not possible to determine the anatomical relationships of a given bronchiole, particularly where only a segment of the airway was available. In the rat all the intrapulmonary bronchi and bronchioles are lined by a single layer of epithelial cells. Bronchioles were classified as proximal or distal using the following criteria. The epithelium of proximal bronchioles was thrown into numerous folds with bands of connective tissue supporting the crest of each fold. It consisted largely of ciliated cells which were markedly columnar in shape. The mucosa was surrounded by a thick wall of smooth muscle among which unmyelinated nerves were prominent. In distal bronchioles the epithelium was not folded, and the cells were cuboidal or no more than three times as high as they were wide, the majority being nonciliated. There were few smooth muscle cells or nerves. Most of these characteristics could be ascertained from the $1 \mu \mathrm{m}$ thick sections by light microscopy.
The fifth group of rats comprised 20 adult males Sprague Dawley rats. They were given intraperitoneato injections of a solution of chlorphentermine hydro-므 chloride dissolved in saline at a dose of $50 \mathrm{mg} / \mathrm{kg} \overline{\bar{s}}$ body weight. The injections were administered dailyळ for six days in each week for a total period of 50 days. On the fiftieth day of the experiment the ratses were killed with intraperitoneal injections of $\overrightarrow{0}$ amylobarbitone sodium. Small blocks of lung tissue were taken from the superior lobe of the right lung $\vec{\omega}$ for electron microscopy as described above. The? bronchus supplying the superior lobe was ligated and $\vec{x}$ the lungs were distended with $10 \%$ formol saline through the trachea until the pleural surfaces were. smooth, and then immersed in a similar solution. After fixation, blocks of lung tissue were embedded $\vec{A}$ in paraffin wax and sections $5 \mu \mathrm{m}$ in thickness were ${ }_{\odot}$ cut and stained with haematoxylin and eosin, periodic acid Schiff's reagent, and the luxol fast blue staining technique as described by Azzopardi and Thurlbeck (1969). Lung tissue from the other four groups of rats was also fixed in formalin, sectioned, and $\stackrel{?}{5}$ similarly stained.

\section{RESULTS}

LIGHT MICROSCOPY OF GROUPS 1 TO 4 Clara cells were easily identified in the terminal bronchioles because they projected further into the lumen than $\frac{O}{D}$ the ciliated cells (Figs 1 and 2). In the more proximal bronchioles Clara cells were seen as

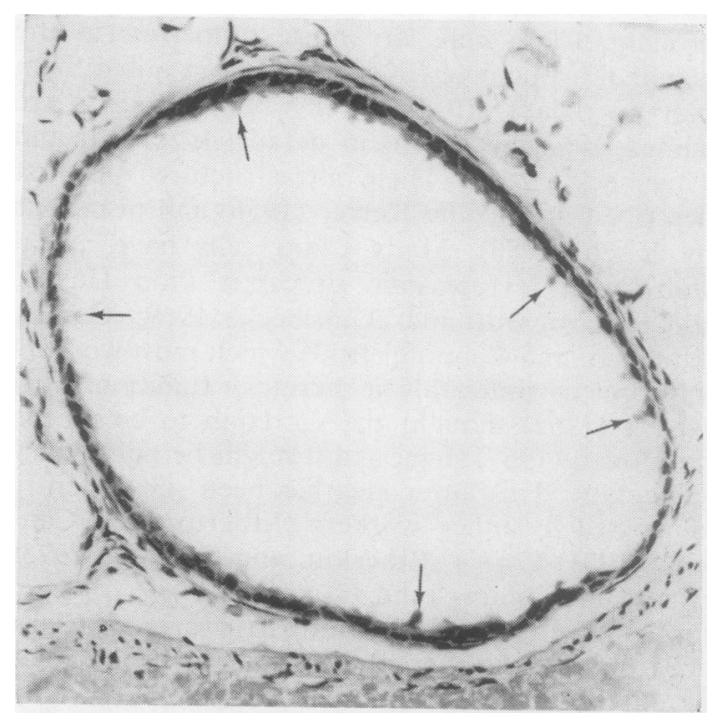

FIG. 1. Adult control rat. Bronchiole from an adult Sprague Dawley rat showing the low columnar epithelium comprising ciliated cells and Clara cells. The latter (arrowed) project further into the lumen than the ciliated cells. (Haematoxylin and eosin $\times 265$.) 


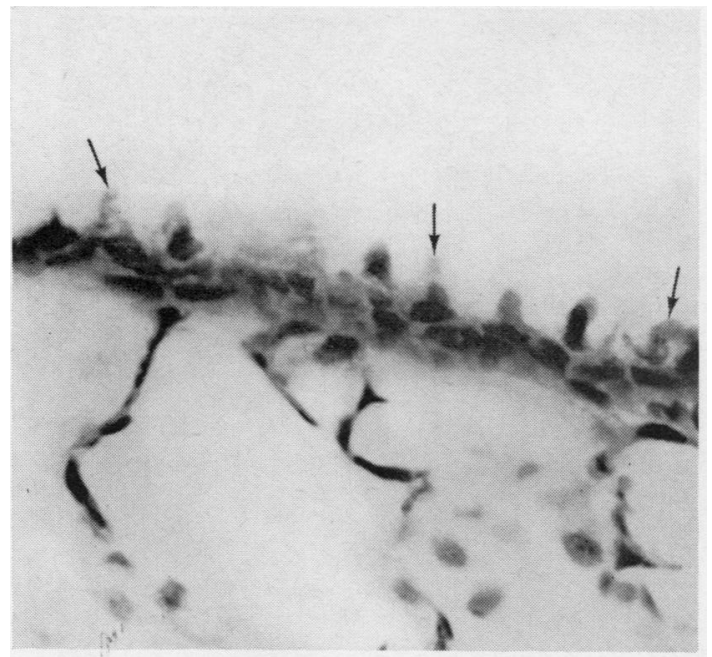

FIG. 2. Adult control rat. Part of a terminal bronchiole adjacent to a respiratory bronchiole. Clara cells are numerous and project into the lumen. Some Clara cells possess apical club-shaped cytoplasmic processes (arrowed). (H. and E. $\times 575$.)

occasional protrusions into the lumen (Fig. 1), but adjacent to respiratory bronchioles they were the predominant epithelial cell (Fig. 2).

Clara cells contained a central dark nucleus above which was an apical region of amorphous eosinophilic cytoplasm. Often apical club-shaped cytoplasmic protrusions were present (Fig. 2). In the recesses of the bronchioles, detached islands of cytoplasm identical with these cytoplasmic protrusions were seen close to the Clara cells. There were few differences in the structure or frequency of Clara cells between the four groups of rats with the exception that apical cytoplasmic protrusions were less common in the neonatal rats. Clara cells were not PAS positive and we were unable to demonstrate convincingly that they stained more deeply with luxol fast blue than the ciliated cells.

\section{ULTRASTRUCTURE IN CONTROL ANIMÁLS}

Adult rats (group 1) Under the electron microscope at low magnifications Clara cells were seen as non-ciliated cells extending further into the bronchiolar lumen than adjacent ciliated cells (Fig. 3). In the proximal bronchioles Clara cells were uncommon except at the crests of folds in the epithelium. In the distal bronchioles Clara cells were numerous and formed the majority of cells in the epithelium. In both classes of bronchiole the ultrastructure of the Clara cells was similar.

The type and distribution of organelles varied in different regions of the cells so that it was possible to divide them into three zones comprising base, middle, and apex (Fig. 4). At the base of each cell there was a prominent basement membrane (Fig. 4) beneath which was the connective tissue of the bronchiolar mucosa. The cytoplasm in the basal zone contained numerous elongated mitochondria, scanty rough endoplasmic reticulum, smooth endoplasmic reticulum, and free ribosomes (Fig. 4). In most Clara cells there were three or four large lysosomes (average diameter $550 \mathrm{~nm}$ ). These were usually circular or occasionally oval in section and were bounded by a membrane (Fig. 4).

The middle zone of the Clara cell contained the nucleus which was elongated and bilobed, the arms of the lobes pointing towards the base of the cell (Figs 3 and 4). This was in contrast to the ciliated cells in which the nucleus was oval and not divided into lobes. On either side of the nucleus there was almost invariably a Golgi apparatus (Figs 4 and 5). In the centre of these Golgi bodies the cisternal spaces were clear but at either edge they contained a pale amorphous material (Fig. 5). Rods and vesicles also containing this material were seen apparently breaking off, or fusing with, the membrane stacks of the Golgi apparatus (Fig. 5). Smooth endoplasmic reticulum was abundant in the middle zone and consisted of short rods and vesicles which contained a pale amorphous substance identical with that seen in the Golgi apparatus. Rough endoplasmic reticulum was also abundant in the middle zone. It consisted of pairs of unbranched membranes with narrow cisternal spaces (Fig. 6). The rough endoplasmic reticulum was situated close to the nucleus surrounding the apical half of it. Its orientation was usually parallel to the nuclear membrane although near the apex of the nucleus it was sometimes arranged in the form of whorls. The cisternae of the rough endoplasmic reticulum bore scanty ribosomes and the cisternal space contained a pale amorphous substance. Ballooning of the cisternae at their edges was sometimes seen (Fig. 6), and the presence of these balloons free within the cytoplasm suggested that they had become detached. Also present in the middle zone were numerous elongated mitochondria, occasional lysosomes, and free ribosomes.

The apical zone of the Clara cells was characterized by a profusion of smooth endoplasmic reticulum, far in excess of that seen elsewhere in 


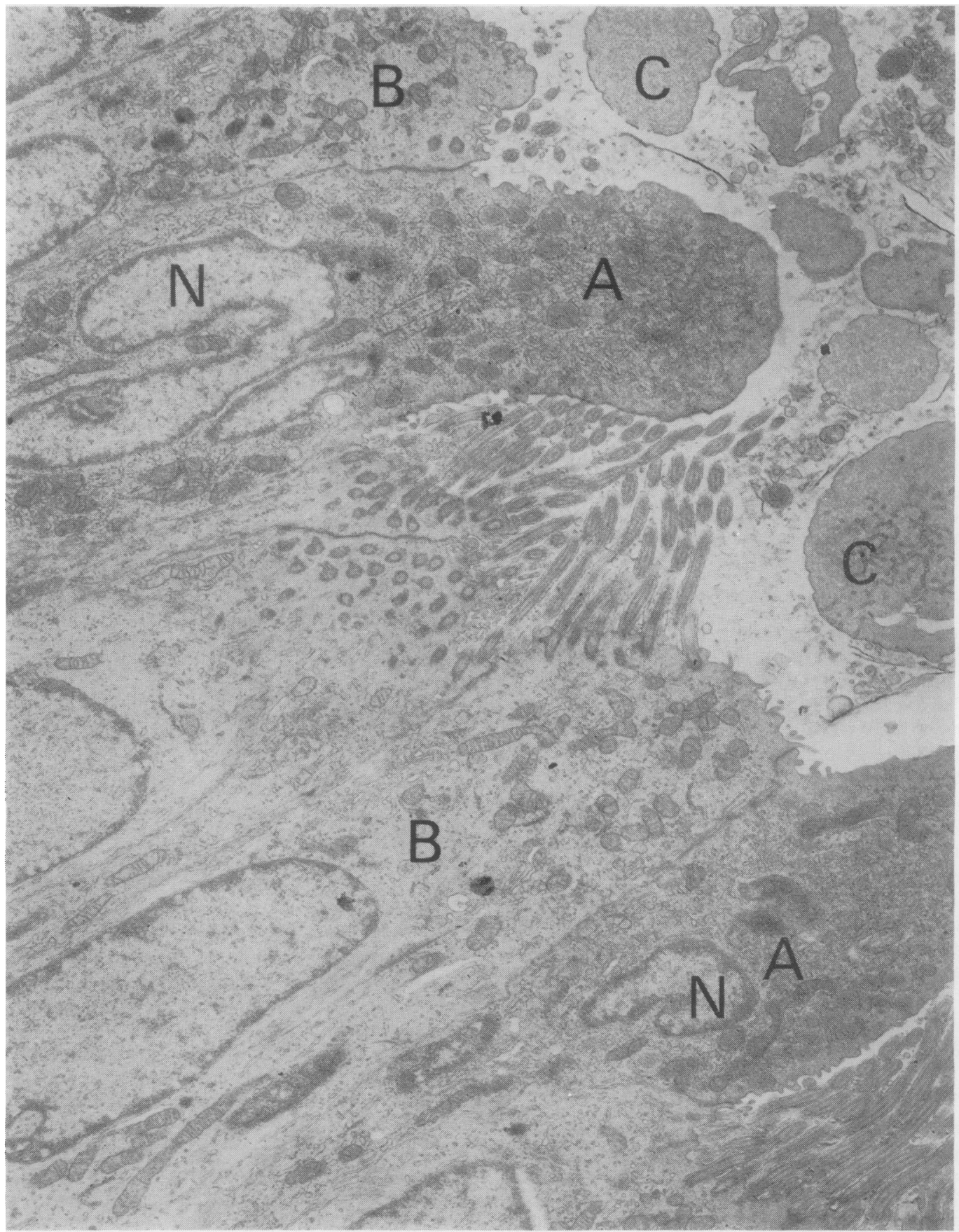

FIG. 3. Adult control rat. Electron micrograph of part of a terminal bronchiole showing ciliated cells $(B)$ and Clara cells $(A)$. Note the bilobed nuclei of the Clara cells $(N)$. The bronchiolar lumen contains detached islands of cytoplasm $(C)$ which have been extruded from the apices of the Clara cells. $(\times 7,500$.) 


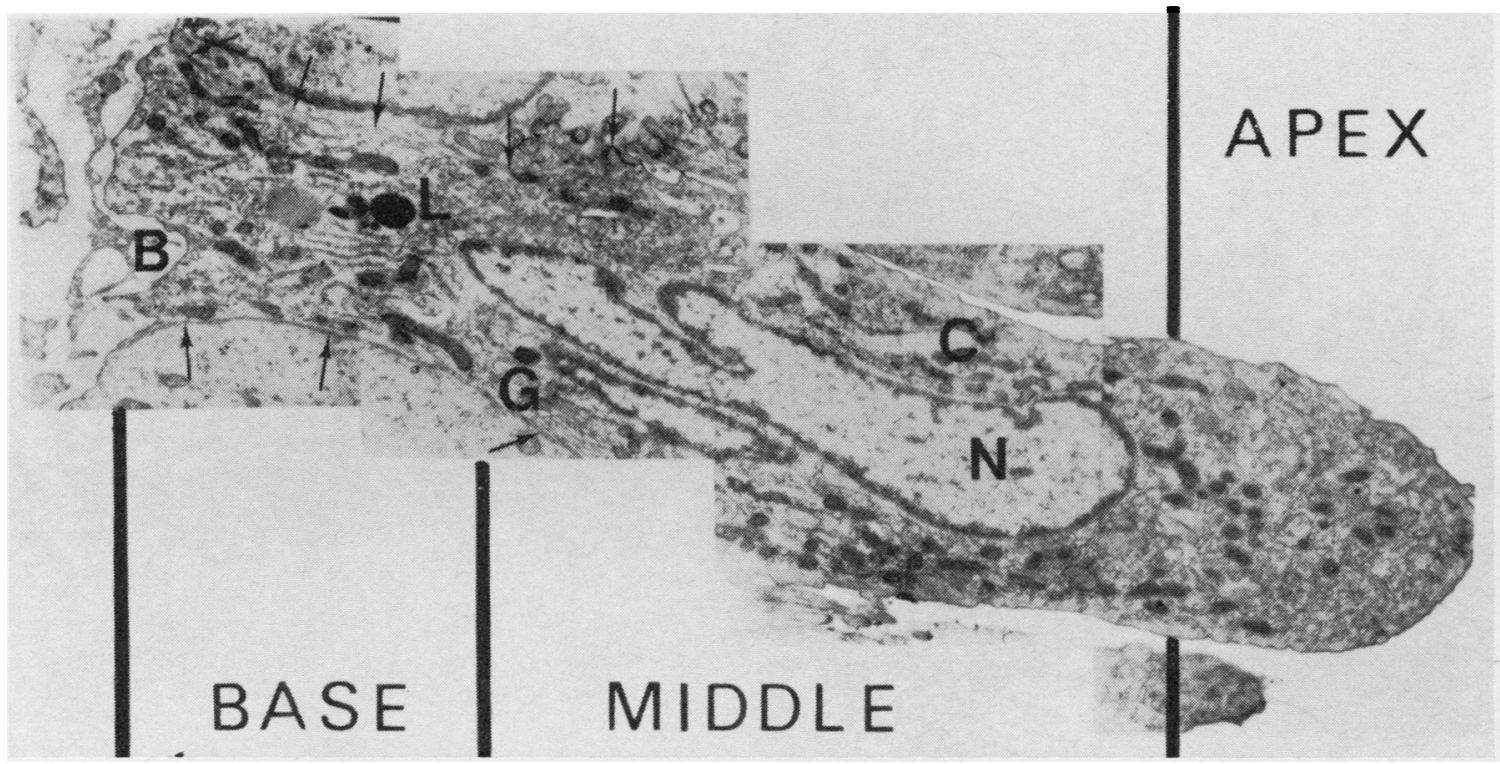

FIG. 4. Adult control rat. Reconstruction montage of electron micrographs to demonstrate that Clara cells can be divided into three zones. The cell rests upon a basement membrane $(B)$ beneath which are fibrocytes. The basal zone contains elongated mitochondria, rough endoplasmic reticulum, and a lysosome $(L)$. The middle zone contains the lobed nucleus $(N), a$ Golgi apparatus $(G)$, and a pale cytoplasmic 'cleft' $(C)$. In the apex there are spherical mitochondria and large quantities of smooth endoplasmic reticulum. The boundary of the cell is indicated by arrows. $($ Approx. $\times 8,000$.)

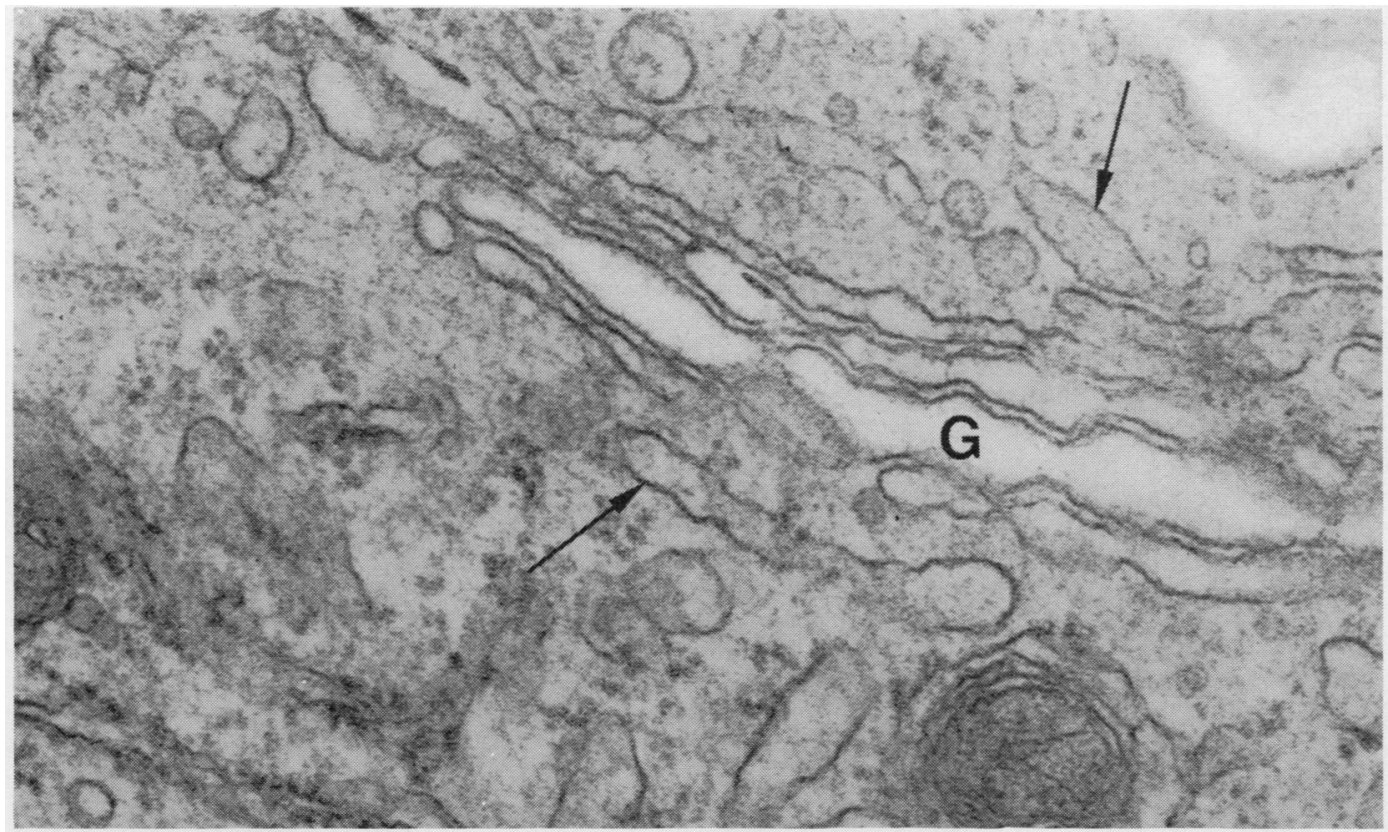

FIG. 5. Adult control rat. Golgi apparatus $(G)$ with closely associated membranes of smooth endoplasmic reticulum (arrowed) containing a pale amorphous substance. (Electron micrograph $\times 75,000$.) 


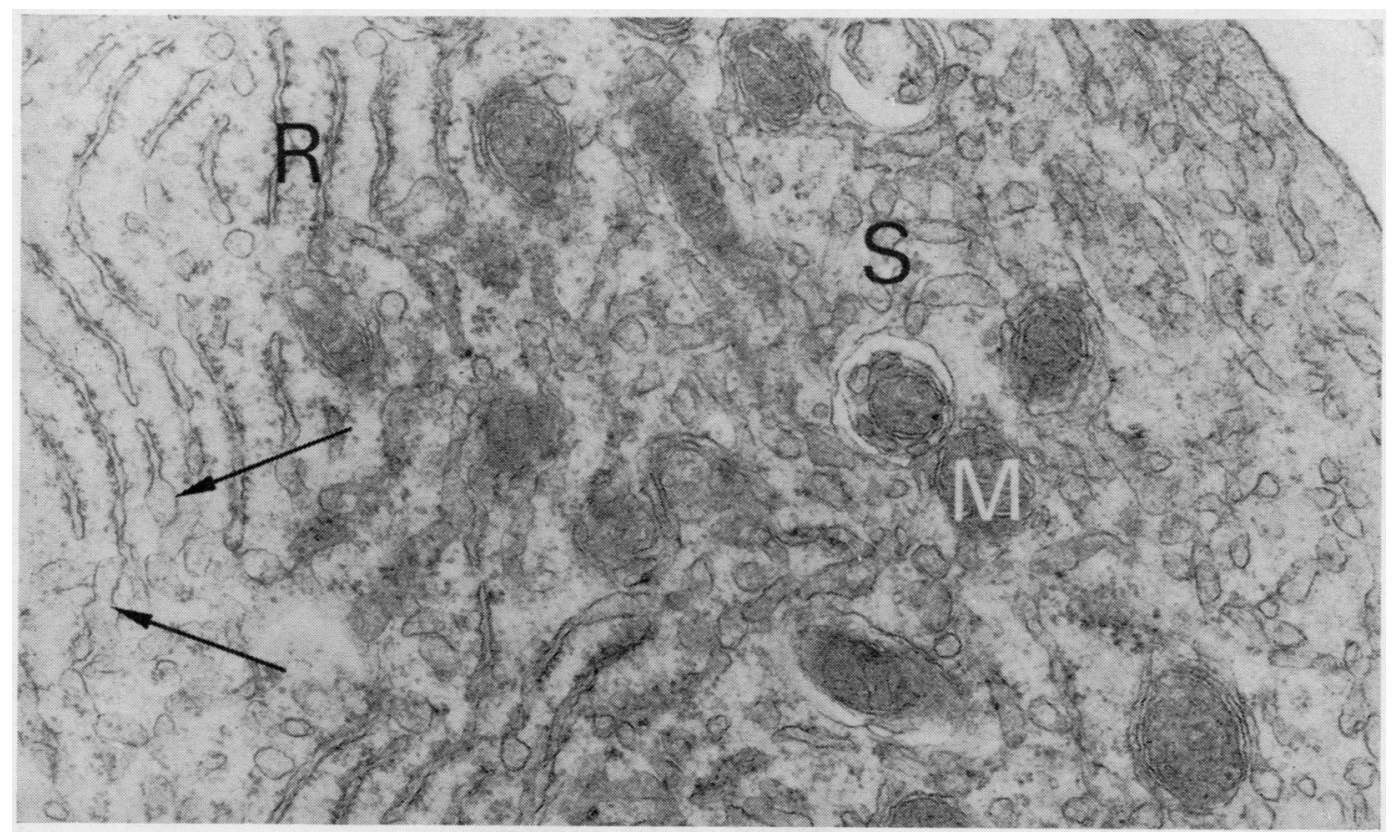

FIG. 6. Adult control rat. Clara cell showing part of the middle zone (to the left) and the apical zone (to the right). There is prominent rough endoplasmic reticulum $(R)$, the edges of which show ballooning (arrowed). Many of these dilatations occur freely in the cytoplasm. The apex of the cell is filled with smooth endoplasmic reticulum $(S)$. Mitochondria $(M)$ contain few cristae and are invested by membranes of the smooth endoplasmic reticulum. (Electron micrograph $\times 37,500$.)

the cell (Fig. 6). The smooth endoplasmic reticulum consisted of vesicles and rods of varying length and these were commonly branched. The space enclosed by the membranes of the smooth endoplasmic reticulum contained a pale amorphous material identical with that seen in other zones of the cell. Mitochondria in the apical zone were typically spherical and were unusual in that they were virtually devoid of cristae (Figs 6 and 7). The smooth endoplasmic reticulum often closely surrounded the mitochondria, giving the latter the appearance of having a multilayered wall (Figs 6 and 7). In the apical zone and sometimes extending into the middle zone there were pale elongated 'clefts' in the cytoplasm (Fig. 4). At high magnification these structures were seen to be bounded by a membrane and they contained the same pale amorphous substance as the smooth endoplasmic reticulum (Fig. 7).

In the distal bronchioles the apical zone of many of the Clara cells projected from the rest of the cell in the form of an apical cap (Fig. 8). The cytoplasm in this cap was less dense than that in the rest of the cell and was sharply demarcated from it. It contained large quantities of smooth endoplasmic reticulum (Fig. 8). The bronchiolar lumen contained a variety of detached islands of cytoplasm (Fig. 3). Some of these were structurally the same as apical caps of Clara cells whereas others lacked cytoplasmic organelles and were disintegrating. There were many intergrades between these two extremes in which there was progressive dissolution of the membranes of the smooth endoplasmic reticulum (Fig. 9). It was sometimes possible to find an apical cap attached to a Clara cell by a narrow isthmus suggesting that the islands of cytoplasm originated by extrusion of the apical caps into the bronchiolar lumen.

Apical caps were also present on some of the Clara cells in the proximal bronchioles but the proportion of cells showing this feature was less than in the distal bronchioles.

Neonatal rats (group 2) Clara cells were numerous in the distal bronchioles of neonatal rats but differed from their counterparts in the adult rats in several respects. The most striking difference was the presence in the Clara cells of neonatal rats of many spherical, membrane-bound, electron-dense bodies (Figs 10 and 11). These inclusions were most numerous in the apical half 


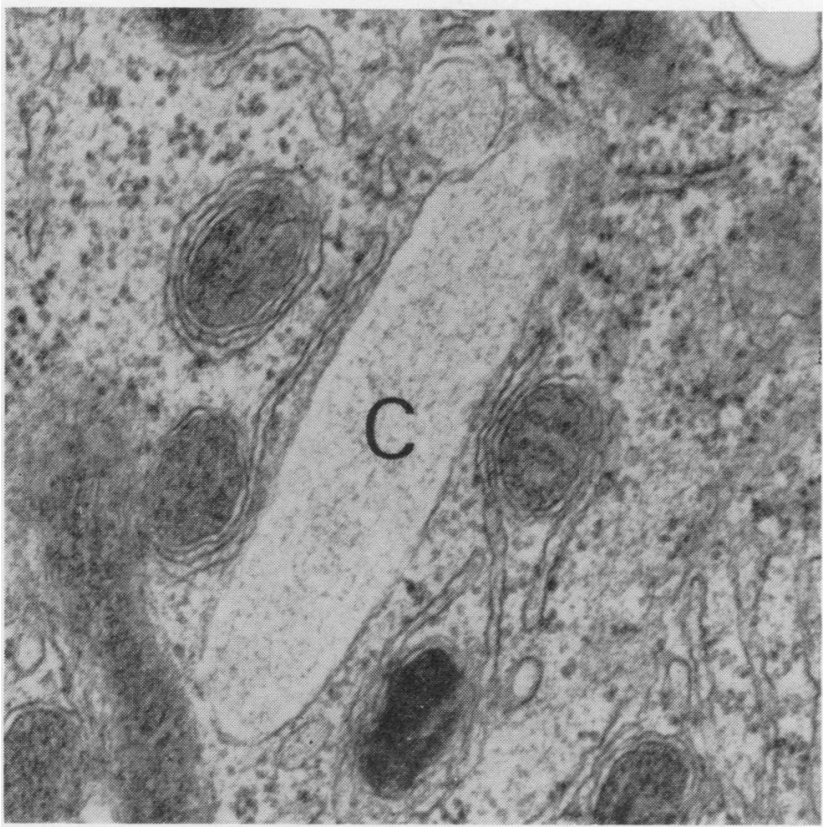

FIG. 7. Adult control rat. Cytoplasmic 'cleft' $(C)$ in the middle zone of a Clara cell. Note that the mitochondria lack cristae and are invested by smooth endoplasmic reticulum. (Electron micrograph $\times 60,000$.)

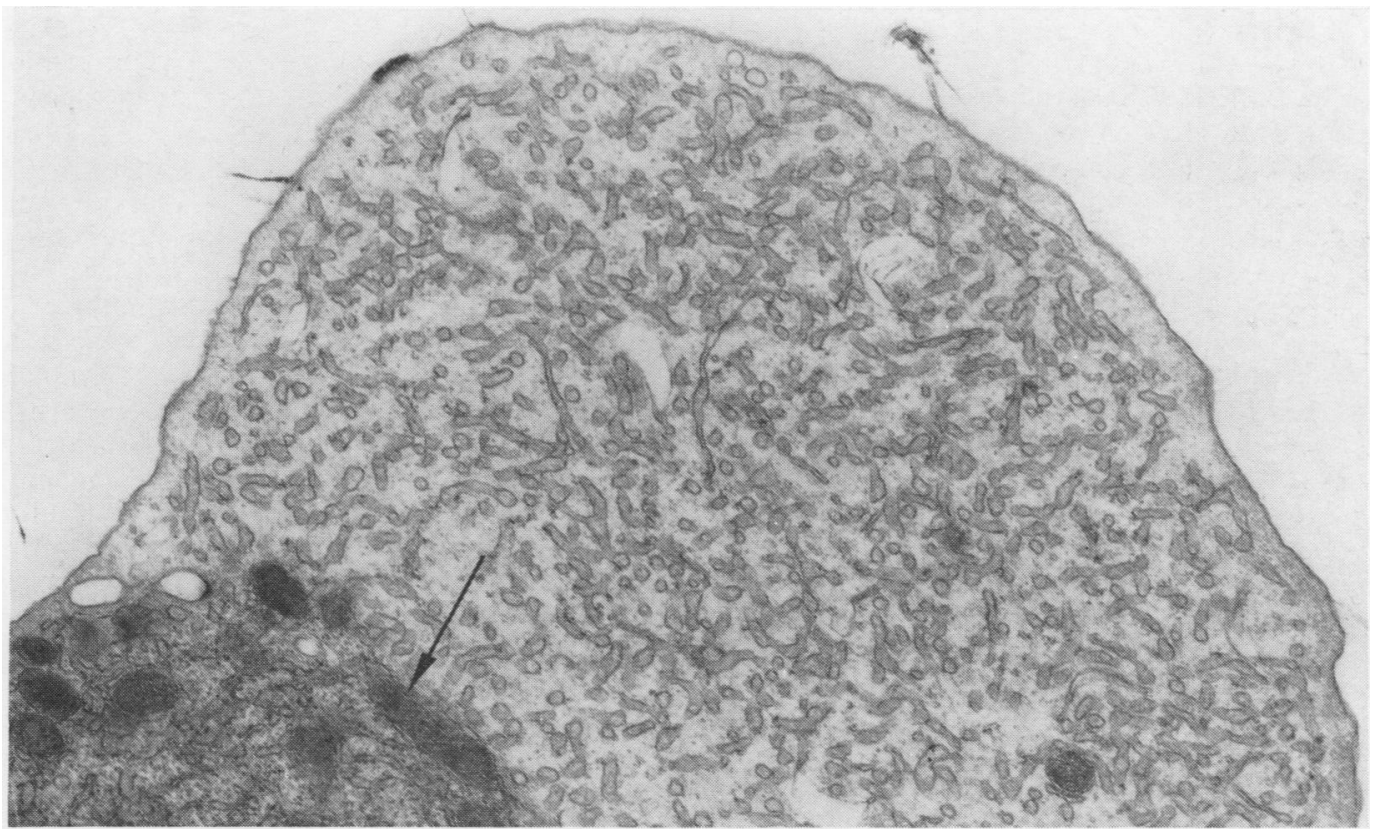

FIG. 8. Adult control rat. Apex of a Clara cell showing a cytoplasmic cap consisting entirely of smooth endoplasmic reticulum, the cisternae of which contain a pale amorphous substance. There is a sharp division between the apical cap and the rest of the cell (arrowed). (Electron micrograph $\times 18,750$.) 


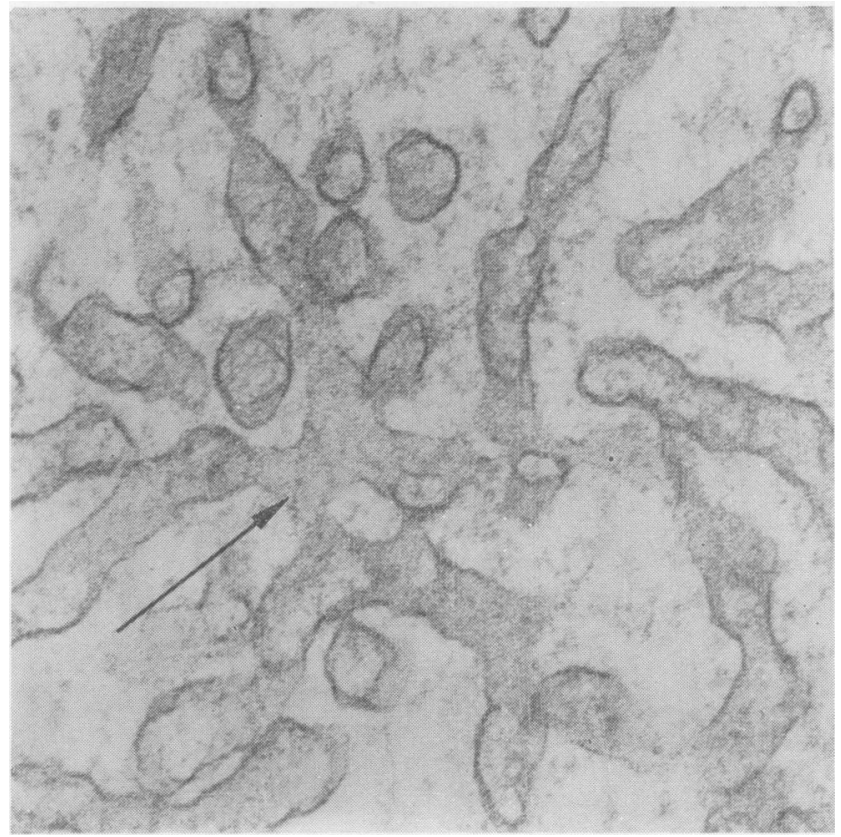

FIG. 9. Adult control rat. Detail of a cytoplasmic extrusion from a Clara cell showing the smooth endoplasmic reticulum containing a pale amorphous substance. There is evidence that the membranes are undergoing dissolution (arrowed). (Electron micrograph $\times 75,000$.)

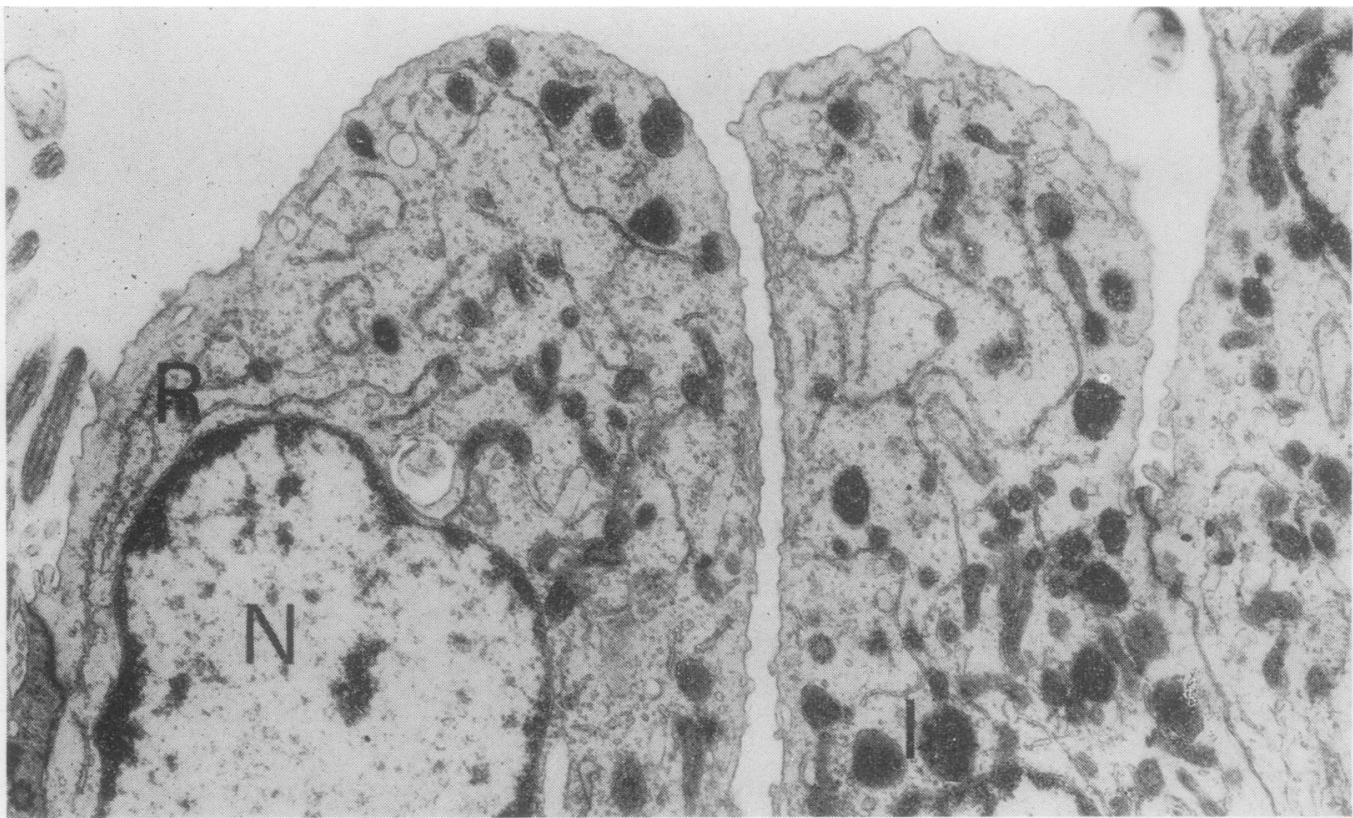

FIG. 10. Neonatal control rat. Two Clara cells showing a nucleus $(N)$, sparsely distributed rough endoplasmic reticulum $(R)$, and dark inclusions $(I)$. Note the almost total absence of smooth endoplasmic reticulum at the apex. (Electron micrograph $\times 12,500$.) 


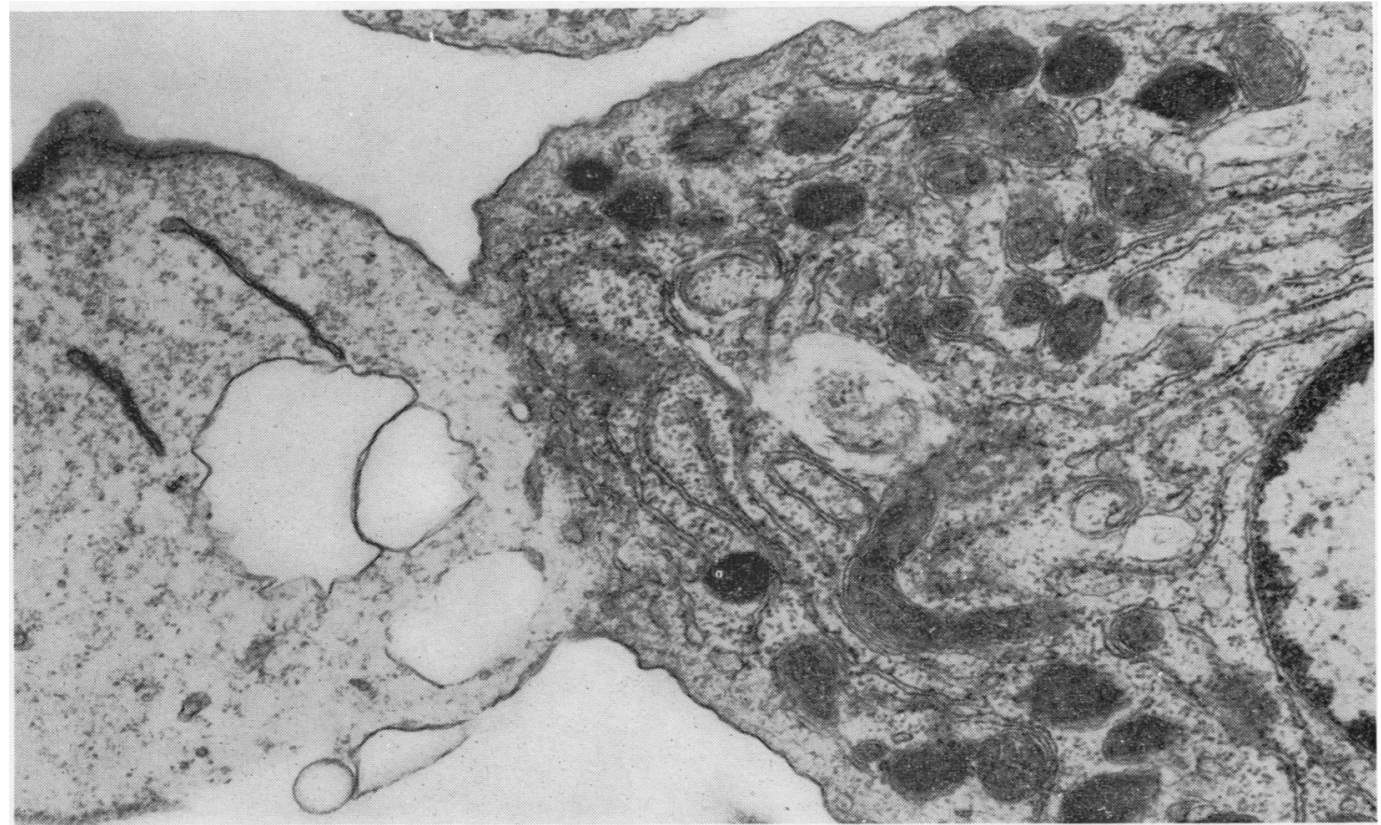

FIG. 11. Neonatal control rat. Clara cell showing the apex caught in the process of extrusion into the bronchiolar lumen. It contains little smooth endoplasmic reticulum. The main body of the cell contains rough endoplasmic reticulum, dark inclusions, and mitochondria. (Electron micrograph $\times 25,000$.)

of the cells and were smaller than the lysosomes of Clara cells in the adults (average diameter $255 \mathrm{~nm}$ ).

The Clara cells in neonatal rats contained prominent but sparsely distributed rough endoplasmic reticulum (Fig. 10). This consisted of long, twisting, unbranched cisternae bearing scanty ribosomes. Unlike that in the adult rats, the rough endoplasmic reticulum was evenly distributed throughout the cells and was not orientated parallel to the nuclear membrane. In a minority of Clara cells the apical region contained an abundance of rough endoplasmic reticulum (Fig. 12) which consisted of narrow cisternae arranged in the form of loops and spirals. A few of these cisternae showed ballooning at their edges. Mitochondria were numerous and in the apical zone they were spherical and invested by smooth-surfaced membranes (Fig. 11). Although mitochondria in the apex appeared to contain less cristae than in the basal region this difference was not as striking as in the adult rats. The profusion of smooth endoplasmic reticulum seen in the apex of Clara cells in adult rats was not a feature of the Clara cells in neonates (Figs 10,11 , and 12). Clefts in the cytoplasm containing a pale amorphous substance were found in a minority of cells but were not as common as in the adult rats. Similarly, extrusions of the cytoplasm into the bronchiolar lumen were uncommon and contained only a few smooth-surfaced membranes (Fig. 11).

Identification of Clara cells in the proximal bronchioles of neonatal rats presented difficulty because a variety of non-ciliated cells was present. Some of these were immature ciliated cells which bore microvilli but lacked cilia and basal bodies. Another type of cell resembled the Clara cell and contained large apical granular inclusions. There were many intergrades of structure between these bodies and the mucus droplets found in mature goblet cells. Where positive identification of Clara cells was possible in the proximal bronchioles, their ultrastructure was identical with that of Clara cells in the distal bronchioles.

\section{ULTRASTRUCTURE IN HYPOXIC ANIMALS}

Adult rats (group 3) Exposure to acute hypoxia induced changes in the Clara cells which were an exaggeration of their normal structure. The process of extrusion of the apical caps into the bronchiolar lumen was greatly enhanced (Fig. 13). Most of the Clara cells possessed large bulbous 


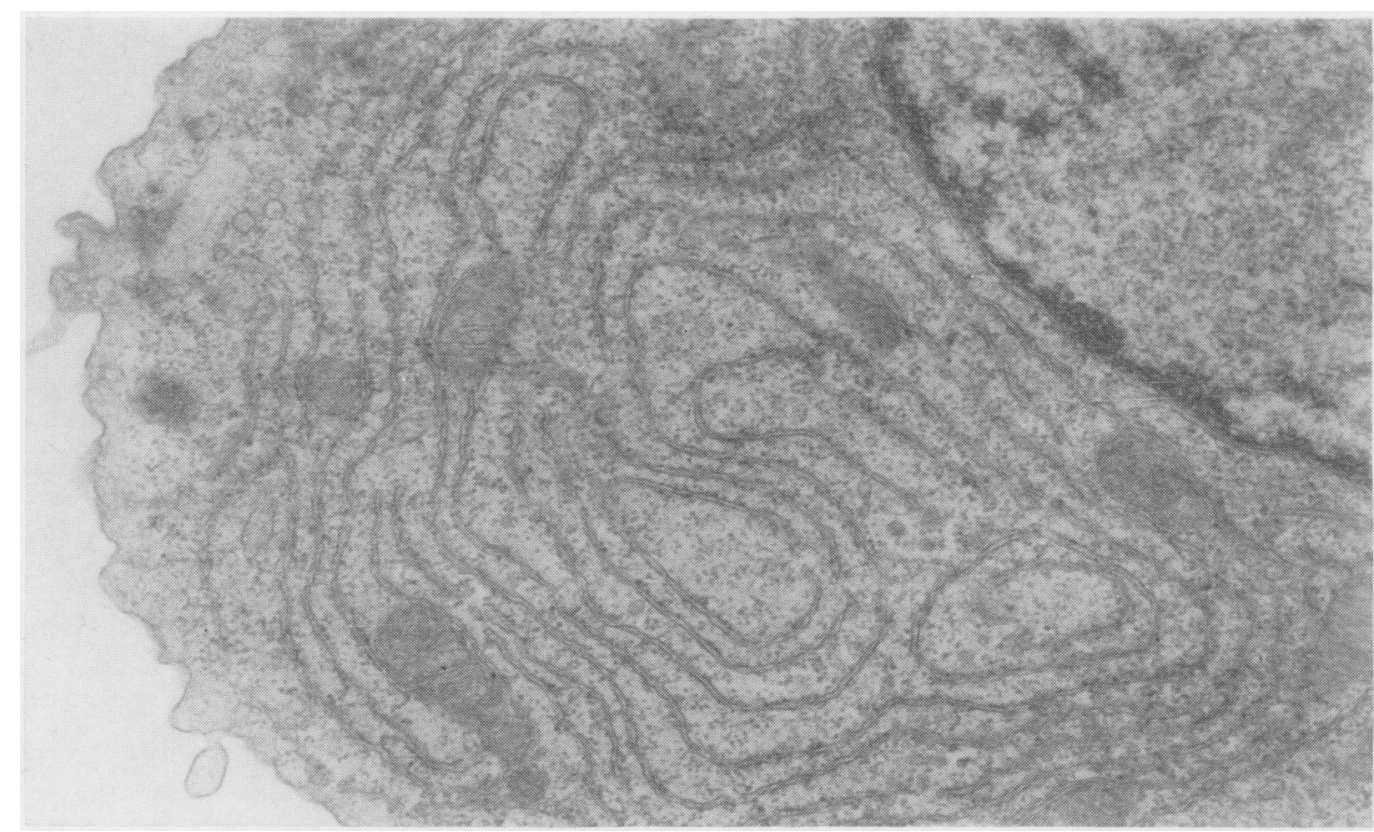

FIG. 12. Neonatal control rat. Apex of Clara cell showing abundant rough endoplasmic reticulum arranged in the form of loops and spirals. Note the absence of smooth endoplasmic reticulum. (Electron micrograph $\times 25,000$.)

apical caps which were distended with smoothsurfaced membranes (Fig. 13) consisting of short, branched rods and vesicles. Many of these were found lying freely in the bronchiolar lumina (Fig. 13) together with detached islands of cytoplasm showing various stages in the dissolution of the smooth endoplasmic reticulum (Fig. 14). Extracellular smooth-surfaced membranes were also found scattered about the bronchiolar lumina (Fig. 14) together with cytoplasmic debris and myelin figures.

With the exception of an apparent increase in frequency of cytoplasmic 'clefts' there were no other alterations in structure of the Clara cells in the hypoxic rats.

Neonatal rats (group 4) The response of the Clara cells of neonatal rats to acute hypoxia was less dramatic. The number of apical extrusions was greater than in the control rats but these did not contain the profuse smooth endoplasmic reticulum of the adult rats. Furthermore, most of the membranes within the extrusions consisted of long, unbranched, narrow cisternae with only a few rods or vesicles (Fig. 15). Large fluid-filled vacuoles were sometimes seen within the cytoplasmic extrusions (Fig. 15).

Within the main body of the Clara cells smooth endoplasmic reticulum was as uncommon as in control neonates. Cytoplasmic 'clefts' were en- $\overrightarrow{\vec{B}}$ countered much more frequently, whereas the electron dense apical inclusions appeared to be less common. Rarely, small lamellated structures were encountered in Clara cells of hypoxic neonatal and adult rats.

EFFECTS OF CHLORPHENTERMINE ON THE CLARA CELL Light microscopy of the bronchioles of rats treated with chlorphentermine revealed a striking hyperplasia of Clara cells (Fig. 16). In addition to this increase in their number, each Clara cell projected further into the bronchiolar lumen than normal. The cytoplasm of the Clara cells had a vesiculated appearance and stained more deeply $N$ with luxol fast blue than the ciliated cells. The alveolar spaces contained large foamy macrophages and debris which also stained faintly with luxol fast blue.

Electron microscopy showed the presence of large inclusions in the cytoplasm of the Clara cells (Figs 17 and 18). These had an average diameter of $4130 \mathrm{~nm}$ and were therefore many times larger than any inclusions found in the Clara cells in the other four groups of rats. These inclusions were of two types, dense homogeneous bodies and lamellated structures (Fig. 18). At 2 intermediate magnifications the dense bodies pre- 


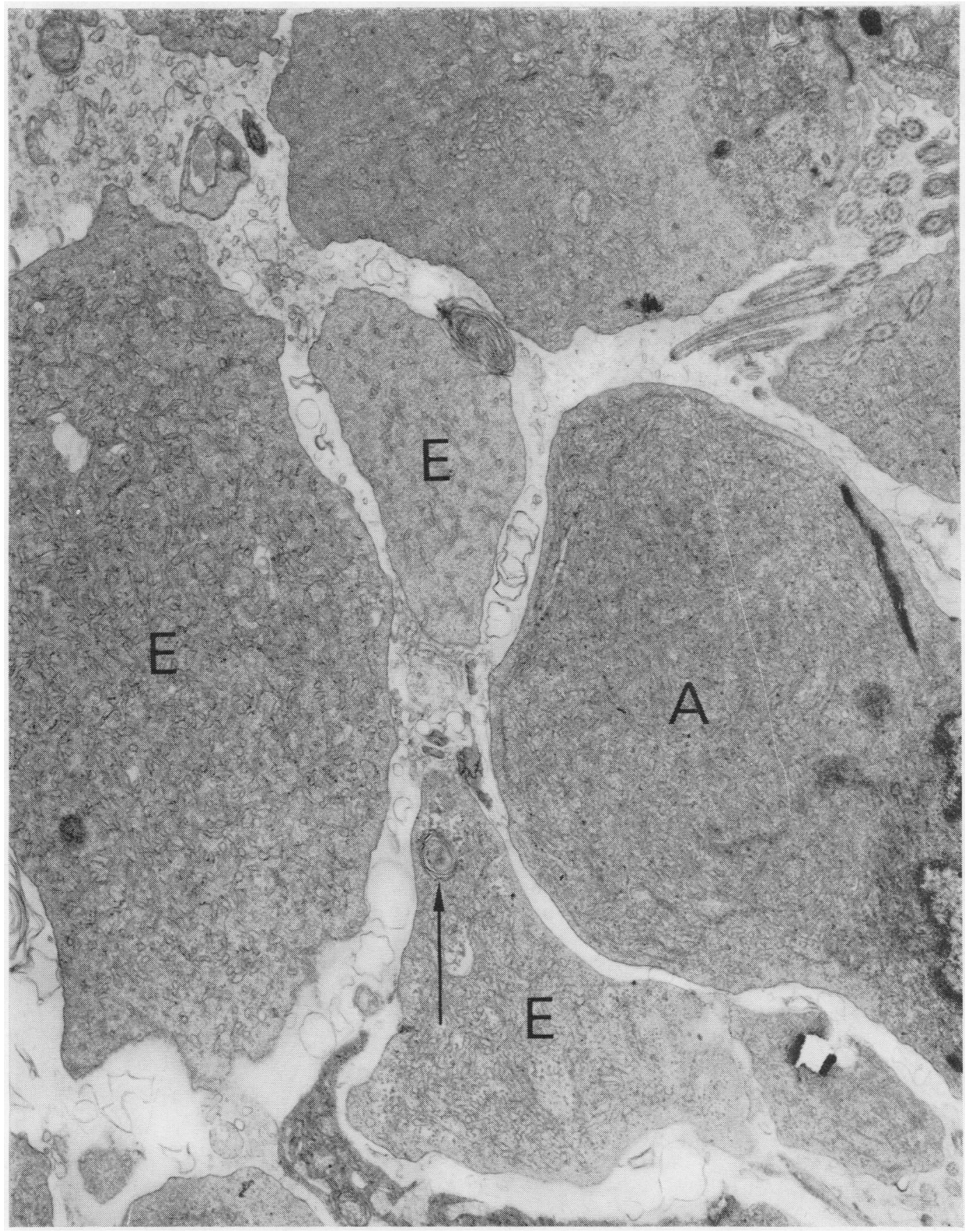

FIG. 13. Adult hypoxic rat. Clara cells possess large apical caps $(A)$ distended with smooth endoplasmic reticulum. These caps have become extruded into the lumen to form islands of cytoplasm $(E)$ which are also filled with smooth endoplasmic reticulum. One such extrusion contains a small lamellated inclusion (arrowed). The bronchiolar lumen also contains cytoplasmic debris. (Electron micrograph $\times 12,500$.) 


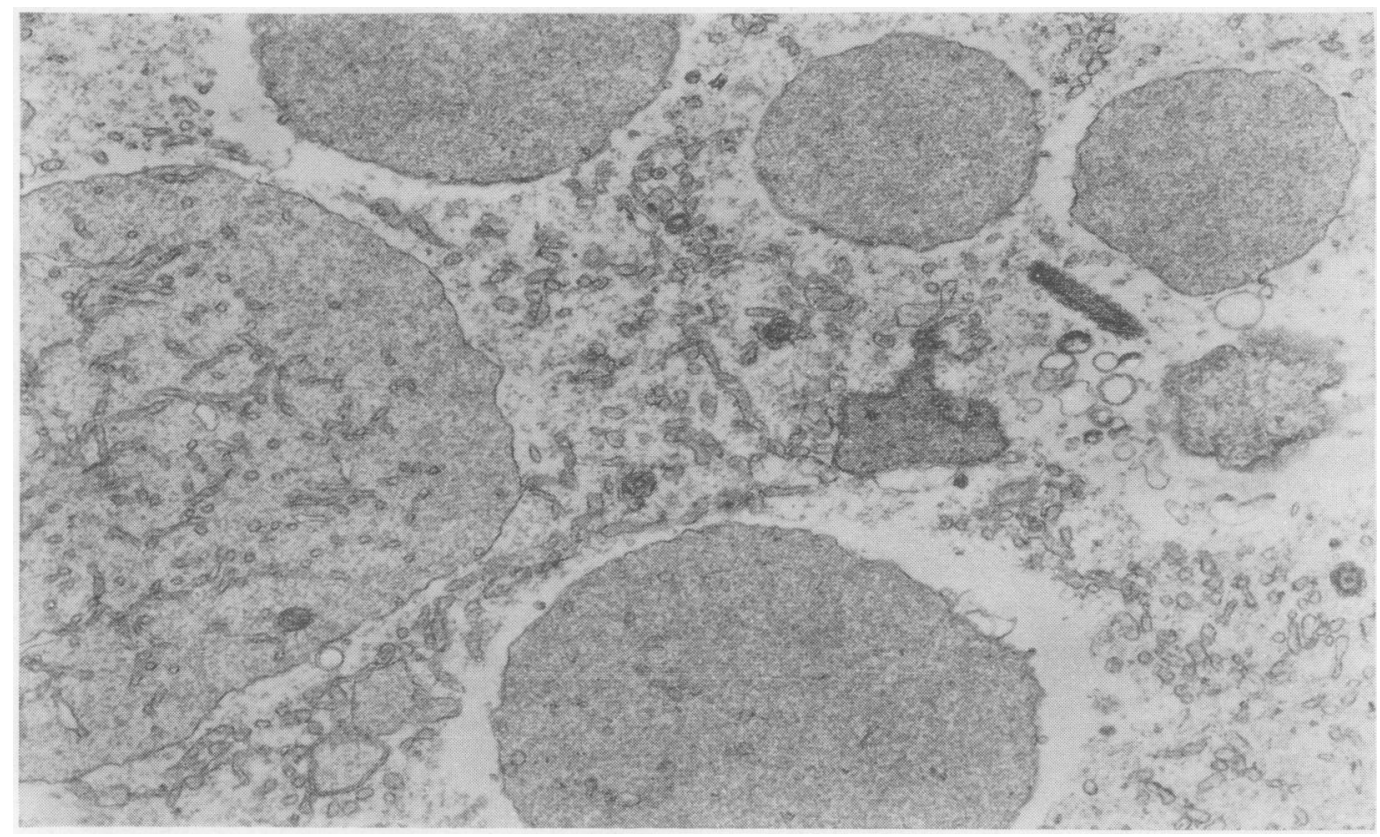

FIG. 14. Adult hypoxic rat. Apical extrusions from Clara cells showing various stages in the dissolution of the smooth endoplasmic reticulum. There are membranes of smooth endoplasmic reticulum free in the bronchiolar lumen. (Electron micrograph $\times 12,500$.)

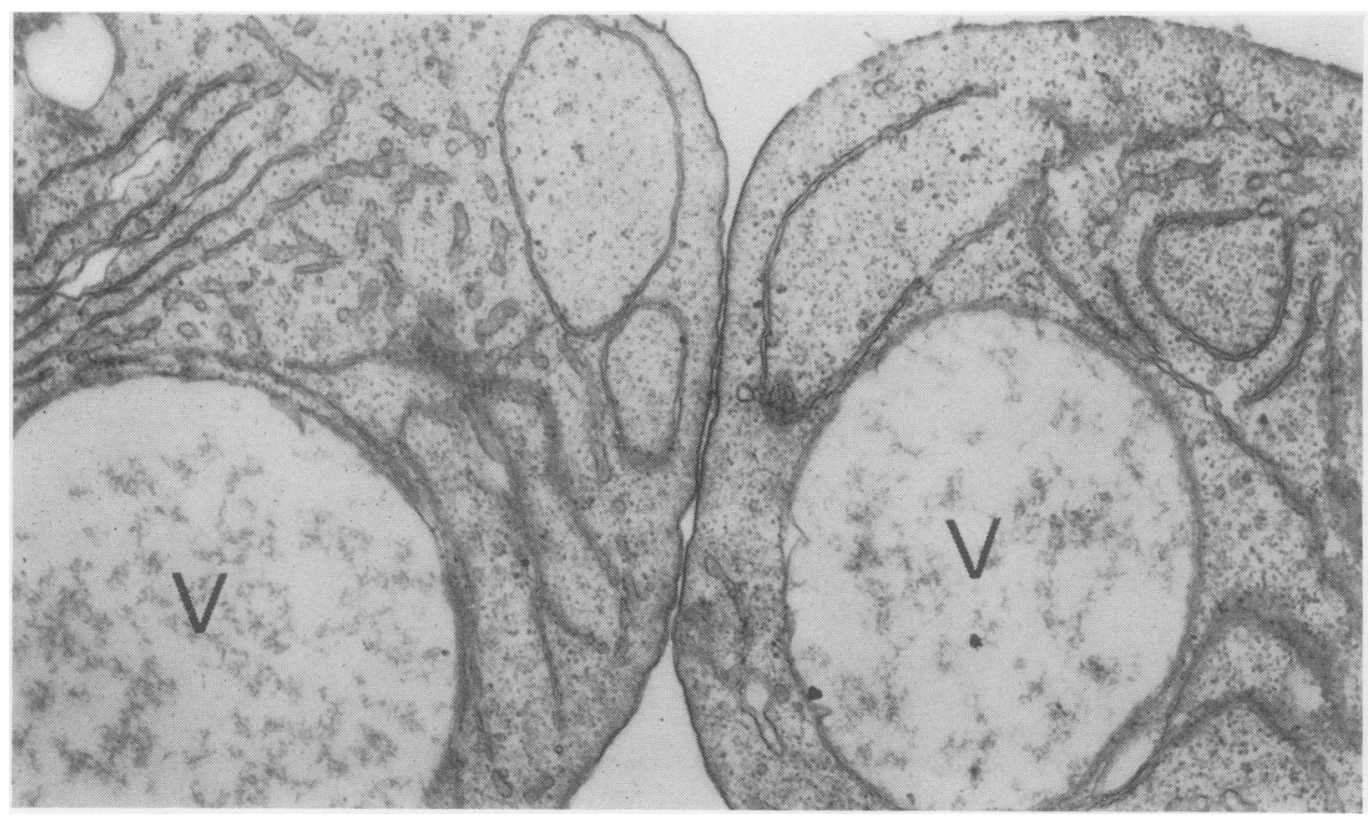

FIG. 15. Neonatal hypoxic rat. Two apical extrusions from Clara cells. The smooth endoplasmic reticulum consists largely of long parallel membranes. Large vacuoles $(V)$ appear to contain oedema fuid. (Electron micrograph $\times 18,750$.) 


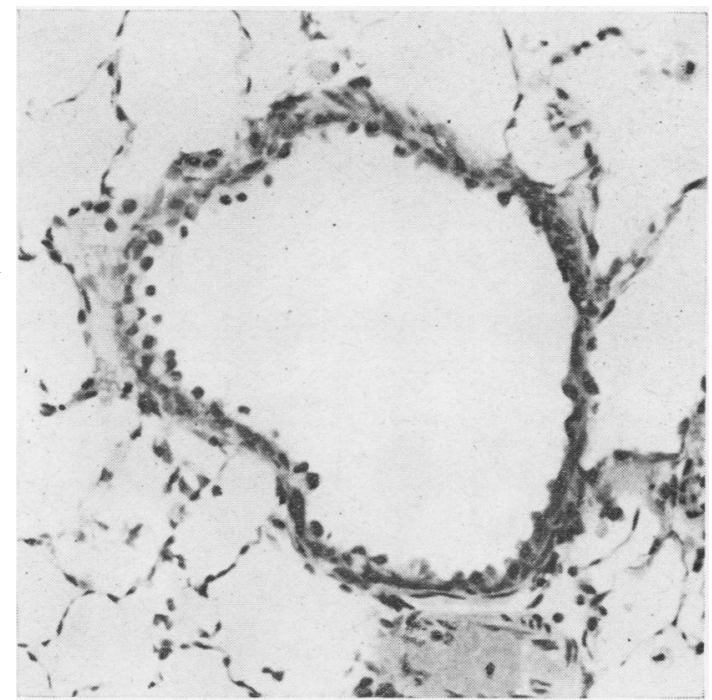

FIG. 16. Adult rat after chlorphentermine administration. Terminal bronchiole showing hyperplasia of Clara cells. Compare with Fig. 1 which shows a normal terminal bronchiole of similar calibre. (H. and $E . \times 275$.)

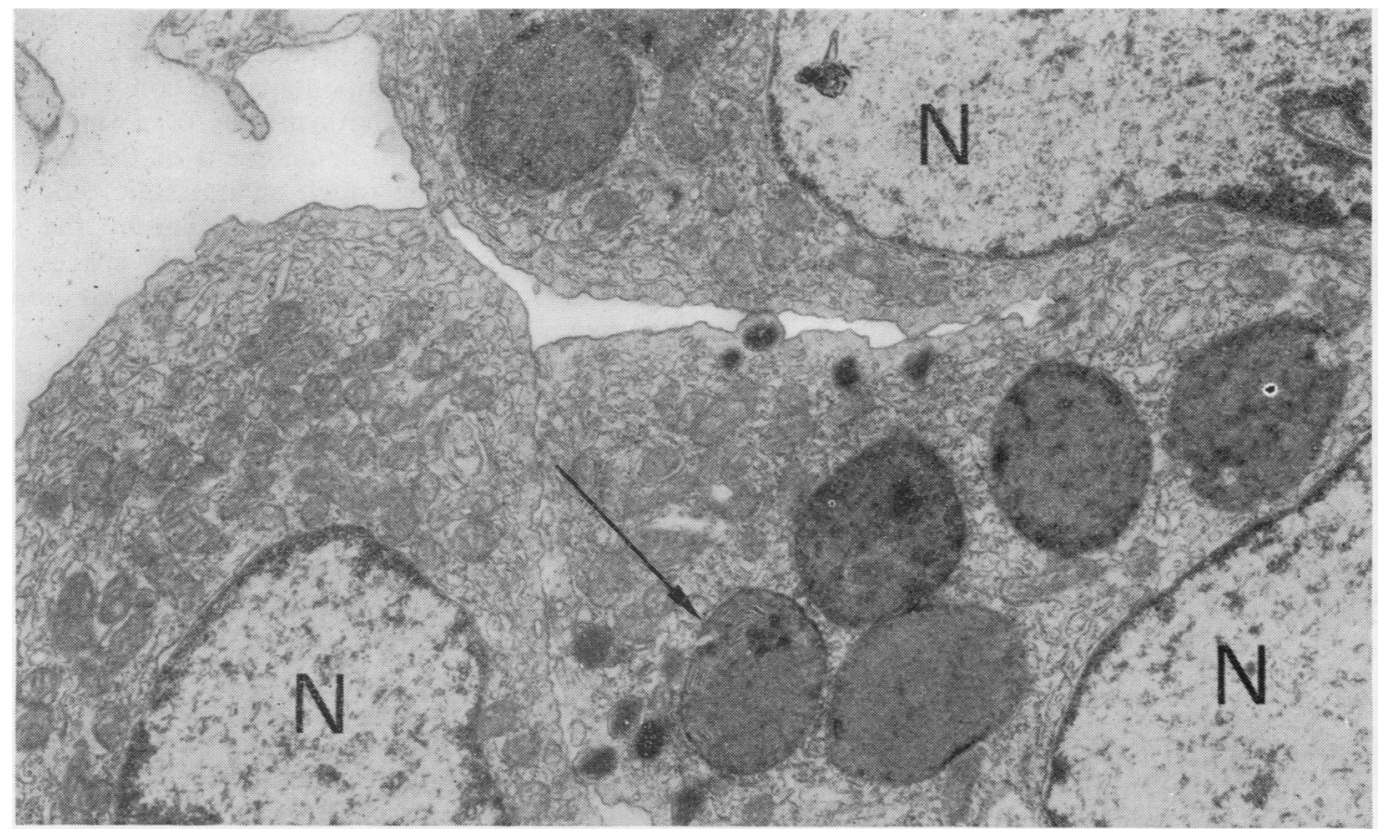

FIG. 17. Adult rat after chlorphentermine administration. Three Clara cells showing nuclei $(N)$ and the presence of large, dense inclusion bodies. One of these (arrowed) shows the development of lamellae at its periphery. Note the large numbers of mitochondria. (Electron micrograph $\times 12,500$.) 


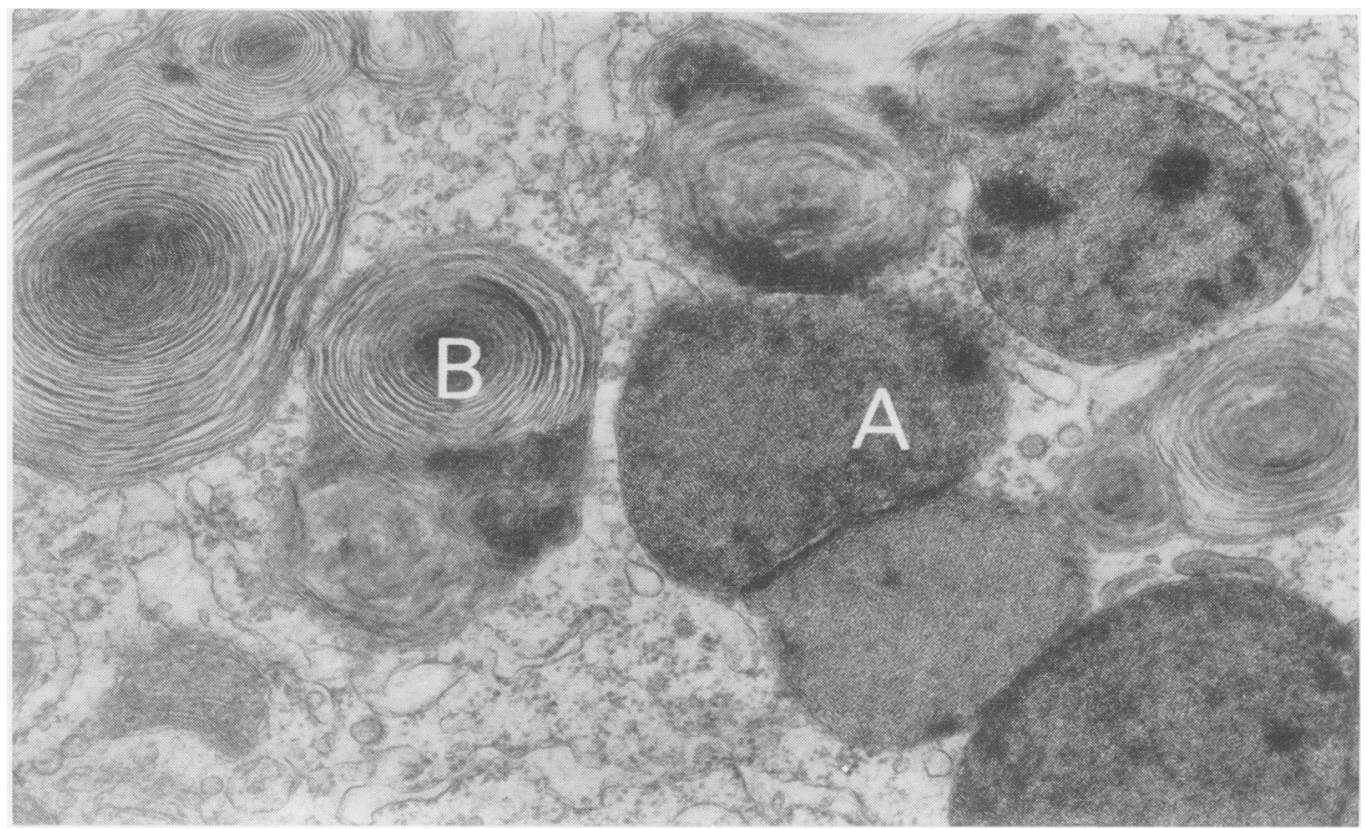

FIG. 18. Adult rat after chlorphentermine administration. A Clara cell showing large dense inclusions $(A)$ and lamellated inclusions $(B)$. Note the stippled appearance of the dense bodies. (Electron micrograph $\times 37,500$.)

sented a stippled appearance (Fig. 18), which at high magnification was shown to be due to a regular arrangement of minute hexagonal globules or tubes. The tubular configuration was restricted to the periphery of the bodies. The lamellated inclusions, on the other hand, consisted of a dense homogeneous core surrounded by concentric electron dense lamellae, the interlammellar distance increasing towards the periphery (Fig. 18). Structures intermediate in appearance between these two inclusions were common, and in these the dense bodies showed the formation of lamellae at their periphery (Fig. 17).

Elsewhere in the Clara cells there was evidence of high metabolic activity in which mitochondria and smooth and rough endoplasmic reticulum were abnormally abundant (Fig. 17). However, protuberant apical caps did not occur as in normal and hypoxic rats.

\section{DISCUSSION}

Our study has confirmed the opinion of other workers that the Clara cell is an active secretory cell. Thus it contains a prominent Golgi apparatus and abundant rough and smooth endoplasmic reticulum. The cisternal spaces of all three of these components contained a pale amorphous substance which may have been a product of secretion. This suggests either that three different $\frac{9}{3}$ secretory products are produced by the cell or that $\overrightarrow{ }$ the three cellular components are concerned with different stages of the synthesis of a single product. Ballooning and detachment of the edges of the cisternae of the rough endoplasmic reticulum $\underset{x}{x}$ was probably the mechanism whereby the syn- $\frac{0}{0}$ thetic product within the cisternal spaces was released into the cytoplasm. Vesicles containing 8 the same pale amorphous substance were closely associated with the Golgi apparatus and were either fusing with, or breaking off, the Golgi stacks. This observation is in agreement with the widely held view that precursors of secretions in many cells fuse with the Golgi body, are coupled $O$ together, and are then released as a finished $N$ product. We suggest that, in the middle zone of N the Clara cell, precursors of the secretion are pro- 0 duced in the rough and smooth endoplasmic reticulum and are coupled in the Golgi apparatus. The final synthesized product contained within $\stackrel{0}{\rightarrow}$ rod-shaped membranes then detaches from the 0 Golgi apparatus and accumulates at the apex of $\overrightarrow{0}$ the cell. Here the membranes do not fuse to form $\mathbb{D}$ secretory granules, as occurs in many types of $\vec{D}$ secretory cell. Instead the apical region of cytoplasm bulges en masse into the bronchiolar lumen 
in the form of an apical cap. These are the ultrastructural equivalent of the club-shaped cytoplasmic processes seen on light microscopy. The apical cap is then extruded into the bronchiole where the endoplasmic reticulum breaks down, presumably permitting the secretion to diffuse into the surrounding cytoplasm. The amorphous island of cytoplasm so produced then disintegrates, thereby releasing the secretory product into the lumen of the bronchiole. The mode of secretion of the Clara cell is therefore a type of apocrine secretion. In reaching this conclusion we agree with Corrin et al. (1973), who noted a similar process in the bronchioles of mice. However, they described dissolution of the apical endoplasmic reticulum before the apical cap became extruded into the bronchiole. The presence of a pale amorphous substance contained within the cytoplasmic 'clefts' suggests that these also contain the product of secretion. They did not have the appearance of secretory granules and were probably distended cisternae of smooth endoplasmic reticulum.

The differences in the ultrastructure of Clara cells between adult and neonatal rats are probably a reflection of the immaturity of the latter. Thus in the proximal bronchioles, in particular, identification of Clara cells was often rendered difficult owing to their similarity to differentiating goblet and ciliated cells. The apical region lacked the profusion of smooth endoplasmic reticulum typical of the adult, and cytoplasmic extrusions were uncommon, small in size, and contained few membranes. Also, in all but a few neonatal Clara cells there was less smooth and rough endoplasmic reticulum in the middle zone than occurred in adult rats. It seems likely, therefore, that the Clara cells in neonatal rats are not fully developed as secretory cells.

The Clara cells respond to the stimulus of hypoxia by an acceleration of the process of extrusion of the apical caps. In the adult rats the apical caps contained an excess of smooth endoplasmic reticulum, suggesting that the synthetic activity of the cells was also increased. The production of cytoplasmic extrusions from the Clara cells of hypoxic neonatal rats was also accelerated but these contained a paucity of smooth endoplasmic reticulum. A possible explanation as to why acute hypoxia should result in hypersecretion of the Clara cell is provided by the work of Castillo and Johnson (1969). They found that the surface tension in the lungs of mice was elevated 45 minutes after exposure to hypoxia. By two hours there was a degree of compensation but the surface tension was still higher than normal. This suggested that acute hypoxia caused a deficiency of pulmonary surfactant which was partially replaced by two hours. If the Clara cell is responsible for the synthesis of pulmonary surfactant one might expect a shortage of this substance in acute hypoxia to act as a stimulus for increased secretion by the Clara cells.

Examination of rats treated with chlorphentermine has provided evidence as to the nature of the apocrine secretion of the Clara cell. Chronic administration of chlorphentermine elicits the accumulation of large foamy macrophages in the alveolar spaces (Heath et al., 1973). Electron microscopy has shown that the alveolar spaces contain large numbers of phospholipid lattices and that the macrophages appear to ingest this substance which accumulates in their cytoplasm in the form of irregular lamellated inclusions (Smith et al., 1973). The macrophages then disintegrate, releasing cytoplasmic debris and lamellated structures into the alveolar spaces and ducts. Lamellated inclusions also find their way into type I alveolar epithelial cells and the capillary endothelium (Smith et al., 1973). Because the type II alveolar epithelial cells, or granular pneumocytes, were abnormally numerous, it was suggested that the alveolar phospholipid in chlorphentermine lung originated from hyperactivity of these cells. For many years the granular pneumocyte has been regarded as the sole source of pulmonary surfactant which accumulated in its characteristic lamellar bodies. This hypothesis was adopted because during embryological development a drop in surface tension in the lungs coincided with the appearance of lamellar bodies (Buckingham and Avery, 1962; Kikkawa, Motoyama, and Gluck, 1968), because radioactive precursors of pulmonary surfactant are taken up by granular pneumocytes (Buckingham, Heinemann, Sommers, and McNary, 1966; Faulkner, 1969) and because diseases involving a deficiency of surfactant also show a shortage of lamellar bodies (Balis, Delivora, and Conen, 1966). However, the striking hyperplasia of Clara cells which we have demonstrated in chlorphentermine intoxication suggests an alternative-that the Clara cell produces a phospholipid pulmonary surfactant.

Etherton et al. (1973) injected tritiated palmitic acid, a radio-active precursor of pulmonary surfactant, into mice. Subsequent electron autoradiography of the lung showed maximal labelling in the endoplasmic reticulum of Clara cells after 3 minutes. Heavy labelling also occurred in the granular pneumocytes but only after one hour. This observation, plus our own findings, strongly 
suggests that the Clara cell secretes pulmonary surfactant.

The large dense bodies and lamellar inclusions which occurred in Clara cells in chlorphentermine intoxication were an abnormal feature. Such inclusions were absent from the control rats and even in the hypoxic animals lamellated inclusions were extremely rare. However, the hexagonal substructure of the dense bodies more closely resembles the physical state adopted by a mixture of phospholipid and water than does the irregular, loose, spiral arrangement of the lamellar bodies in granular pneumocytes (Luzzati and Husson, 1962). It may be that the metabolism of the Clara cells is altered by chlorphentermine so that these abnormal bodies are formed. Alternatively, an excessive synthesis of phospholipid may lead to its deposition in the cytoplasm of the Clara cells.

Azzopardi and Thurlbeck (1969) found that the Clara cells of mice stain more deeply with luxol fast blue than the surrounding cells. We were unable to reproduce their results in rats except in those animals given chlorphentermine. Luxol fast blue is believed to demonstrate lipoprotein (Pearse, 1968). Azzopardi and Thurlbeck (1969), using a variety of histochemical stains, came to the conclusion that the Clara cell contained lipoproteins rich in choline-containing phospholipids. They took the view that this lipoprotein is the pulmonary surfactant.

If it is true that the Clara cell secretes the pulmonary surfactant, what then is the function of the granular pneumocyte? It may also produce pulmonary surfactant, perhaps of a different chemical nature, since it too takes up labelled palmitic acid. Niden (1967) has stated that the granular pneumocyte is phagocytic but this has been disputed by Corrin (1970). The periphery of lamellar bodies has been shown to contain acid phosphatase (Corrin, Clark, and Spencer, 1969; Kuhn, 1968) which suggests that they may be phagosomes. Also the granular pneumocytes show less oxidative enzyme activity than the bronchiolar epithelium (Azzopardi and Thurlbeck, 1967), and active secretory activity in granular pneumocytes has not yet been convincingly demonstrated. It is clear that the evidence in favour of the granular pneumocyte being the producer of pulmonary surfactant has now been balanced by a weight of opposing evidence. Attention must now be focused on the Clara cell as a possible source of this substance. In particular, the pathology of the Clara cell in diseases involving a deficiency of pulmonary surfactant such as the idiopathic respiratory distress syndrome should be examined.
Professor Heath acknowledges with gratitude the receipt of a grant from the Nuffield Foundation to support this research.

\section{REFERENCES}

Azzopardi, A. and Thurlbeck, W. M. (1967). The oxidative enzyme pattern in developing and adult mice and adult rabbits. Laboratory Investigation, 16, 706.

and (1969). The histochemistry of the nonciliated bronchiolar epithelial cell. American Review of Respiratory Disease, 99, 516.

Balis, J. U., Delivora, M., and Conen, P. E. (1966). Maturation of postnatal human lung and the idiopathic respiratory distress syndrome. Laboratory Investigation, 15, 530.

Buckingham, S. and Avery, M. E. (1962). Time of appearance of lung surfactant in the foetal mouse. Nature, 193, 688.

Heinemann, H. O., Sommers, S. C., and McNary, W. F. (1966). Phospholipid synthesis in the large pulmonary alveolar cell. Its relation to lung surfactants. American Journal of Pathology, 48, 1027.

Castillo, Y. and Johnson, F. B. (1969). Pulmonary surfactant in acutely hypoxic mice. Laboratory Investigation, 21,61 .

Corrin, B. (1970). Phagocytic potential of pulmonary alveolar epithelium with particular reference to surfactant metabolism. Thorax, 25, 110.

—, Clark, A. E., and Spencer, H. (1969). Ultrastructural localization of acid phosphatase in the rat lung. Journal of Anatomy, 104, 65.

- Etherton, J. E., and Conning, D. M. (1973). Apocrine secretory activity in the terminal bronchiole of mouse lung: morphological evidence. Proceedings of the Pathological Society of Great Britain and Ireland. Journal of Pathology, 109, Pv.

Etherton, J. E. and Conning, D. M. (1971). Early incorporation of labelled palmitate into mouse lung. Experientia, 27, 554.

$\longrightarrow,-$, and Corrin, B. (1973). Apocrine secretory activity in the terminal bronchiole of mouse lung: ultrastructural autoradiographical evidence. Proceedings of the Pathological Society of Great Britain and Ireland. Journal of Pathology, 109, Pv.

Faulkner, C. S. (1969). The role of the granular pneumocyte in surfactant metabolism. Archives of Pathology, 87, 521.

Hayek, H. von (1962). Cellular structure and mucus activity in the bronchial tree and alveoli. In Pulmonary Structure and Function. Ciba Foundation Symposium. Ed. by A.V.S. de Reuck and M. O'Connor. Churchill, London.

Heath, D., Smith, P., and Hasleton, P. S. (1973). The effects of chlorphentermine on the rat lung. Thorax, 28, 551 .

Karrer, H. E. (1956). Electron microscopic study of bronchiolar epithelium of normal mouse lung. Experimental Cell Research, 10, 237.

Kikkawa, Y., Motoyama, E. K., and Gluck, L. (1968). Study of the lungs of fetal and newborn rabbits. American Journal of Pathology, 52, 177. 
Kisch, B. (1958). Electron microscopy of the lungs in acute pulmonary edema. Experimental Medicine and Surgery, 16, 17.

Kuhn, C. (1968). Cytochemistry of pulmonary alveolar epithelial cells. American Journal of Pathology, 53, 809.

Luzzati, V. and Husson, F. (1962). The structure of the liquid-crystalline phases of lipid-water systems. Journal of Cell Biology, 12, 207.

Moosavi, H., Smith, P., and Heath, D. (1973). The Feyrter cell in hypoxia. Thorax, 28, 729.

Niden, A. H. (1967). Bronchiolar and large alveolar cell in pulmonary phospholipid metabolism. Science, 158, 1323.

Pearse, A. G. E. (1968). Histochemistry, Theoretical and Applied, 3rd ed., vol. 1. pp. 426-427. Churchill, London.

Smith, P., Heath, D., and Hasleton, P. S. (1973). Electron microscopy of chlorphentermine lung. Thorax, 28, 559.

Requests for reprints to: Professor Donald Heath, Department of Pathology, The University, Liverpool, L69, 3BX. 